\title{
BREVES CONSIDERAÇÕES ACERCA DA INCLUSÃO ESCOLAR
}

\author{
BRIEF CONSIDERATIONS ABOUT SCHOOL INCLUSION
}

\section{Angela Dallafavera da Rosa}

Professora da Rede Pública de Ensino do Município de Ijuí, RS, Brasil. E-mail: angela_ijui@hotmail. com

\section{Carla Simone Hamm Sparrenberger}

Professora da Rede Pública de Ensino do Município de Ijuí, RS, Brasil. E-mail: cspa.carla@gmail.com

\section{Luciana Schuster Scheren}

Professora da Rede Pública de Ensino do Município de Ijuí, RS, Brasil. E-mail: luscherenbio25@gmail. com

\section{Sandra Gabbi Pezzetta Roncata}

Professora da Rede Pública de Ensino do Município de Ijuí, Ijuí, RS, Brasil. E-mail: sanron@bol.com. br

DOI: https://doi.org/10.46550/amormundi.v2i4.113

Recebido em: 20.05.2021

Aceito em: 24.06.2021

Resumo: A inclusão se constitui em um grande desafio para os professores. Adequar os currículos escolares às necessidades individuais dos alunos com necessidades especiais requer estudo, formaçáo continuada, dedicaçáo. Atender aos objetivos previstos na legislaçáo vigente referentes à garantia de escolarizaçáo regular, requer além da formação docente, mudanças na estrutura física das escolas que possibilitem a acessibilidade, a adequação de materiais, rotinas, enfim o atendimento das demandas de pessoal e material que propiciem a real inclusão criando possibilidades de avanço aos alunos incluídos a partir de suas individualidades.

Palavras-chave: Inclusão. Professor. Diversidade. Educação. Transformação. Desafios.

Abstract: Inclusion is a major challenge for teachers. Adapting the school curriculum according to the individual needs of the special needs students demand study, continuous education and dedication. In addition to teacher training, changes in the school facilities, which make accessibility possible, adequate materials, routines and finally, the fulfillment of the demands of personnel and materials that facilitate the achievement of the objectives established in current legislation regarding the guarantee of regular schooling are essential for effective inclusion, which creates possibilities of promotion to the included students based on their individual needs.

Keywords: Inclusion. Teachers.Diversity. Education. Transformation. Challenges. 


\section{Introduçáo}

O debate sobre a diferença, a diversidade cultural e a inclusão de alunos com necessidades especiais, tem ocupado um grande espaço nos discursos políticos e nas pesquisas em educação. O presente trabalho constitui-se de uma reflexão e análise do processo escolar inclusivo ao qual nos deparamos atualmente. Pretende levar à reflexão sobre a realidade escolar, e o aspecto legal abordado pela Declaração de Salamanca, LDB entre outras.

Os objetivos principais da Educação Especial na Perspectiva da Educação Inclusiva são garantir o acesso, a participação e a aprendizagem dos alunos com deficiências, transtornos globais do desenvolvimento e altas habilidades, de forma que escolas públicas ou particulares ofereçam: atendimento educacional especializado; continuidade da escolarização nos níveis mais elevados de ensino; formação de professores para o atendimento educacional especializado e dos demais profissionais da educação para a inclusão escolar; participação da família e da comunidade; acessibilidade urbanística, arquitetônica, nos mobiliários e equipamentos, nos transportes, na comunicação e informação; articulação intersetorial tendo em vista a implementação das políticas públicas.

A implementação das açóes, são essenciais para o processo de inclusão escolar. $\mathrm{O}$ acesso ao currículo e promoção da aprendizagem são de responsabilidade dos sistemas educacionais, sejam públicos ou particulares. Alguns pais desconhecem que as escolas particulares têm as mesmas responsabilidades que as escolas públicas quanto à garantia do direito à educação e ao atendimento às necessidades educacionais especiais. Assim, a oferta de educação especial passa a integrar a proposta pedagógica das escolas. Para que aconteça de fato a inclusão escolar das crianças com necessidades educativas especiais, as escolas devem ser reestruturadas em diversos aspectos: professores capacitados, abertos a novos desafios, revendo e recriando suas práticas educativas; currículos adaptados visando estimular, desenvolver habilidades e capacidades; mudanças estruturais e físicas nas escolas que promovam a acessibilidade e, recursos financeiros e materiais, que viabilizam a sustentação das mudanças necessárias.

Segundo Ribeiro, a perspectiva da inclusão exige o repensar da prática docente e de suas dimensões, bem como de suas repercussôes na organização curricular e na avaliação (RIBEIRO, 2003 pág. 41).

\section{Metodologia}

A fonte de dados para a elaboração do trabalho é descritiva, com base na abordagem qualitativa (LÜDKE; ANDRÉ, 1986) utilizando método exploratório como procedimento de pesquisa bibliográfica.

As reflexôes aqui apresentadas têm como aporte teórico-metodológicos aspectos da inclusão escolar apresentados na Declaração de Salamanca e na Lei de Diretrizes e Bases da Educação Nacional e demais autores que versam sobre o tema abordado. 


\section{Resultados e discussóes}

A educação inclusiva deve constituir-se como uma prática com características e princípios bem definidos, porém que permitam ao longo do processo de implementação na escola, revisões, redefinições e ressignificações (BEYER, 2006), possibilitando que o aluno com necessidades educacionais especiais alcance avanços de desenvolvimento que justifiquem a sua inclusão na escola. Trabalhar na escola numa perspectiva inclusiva é um desafio. Um propósito de querer, tentar, pensar, dedicar-se e fazer, uma escola que inspire a troca de experiências entre os alunos, confronte formas desiguais de pensamento, busque metodologias interativas, faça do reconhecimento da diversidade estratégias para uma nova maneira de olhar o aluno e que o conceba por inteiro e respeite a dignidade de cada um.

O sistema educacional brasileiro defende uma educação para todos por meio de uma escola heterogênea, pluralista e acolhedora, independentemente de suas diferenças. Acredita-se que um currículo adaptável possa oferecer contribuiçóes. A educação inclusiva envolve o preparo das instituiçóes para receber estes alunos e todos os outros, revendo e reformulando currículos, metodologias, adequando espaços físicos, recursos didáticos e principalmente investindo na formação de professores.

A formação dos professores necessita ser permanente. Acreditamos que investir na formação irá facilitar a implementação da proposta de educação inclusiva, a qual envolve toda uma preparação do professor que com base nas dificuldades e diferenças do aluno, buscará novas formas de ensinar e de aperfeiçoar o seu trabalho desenvolvido em sala de aula, estando melhor qualificado para atender as diversidades apresentadas pelos alunos.

Mantoan (1997) discute a importância do profissional da educação respeitar a individualidade de cada educando e que a inclusão é a fusão do ensino regular com o especial. É preciso ter um olhar especial para que nestas salas aconteçam trocas de valores sociais, culturais e intelectuais ocorrendo de fato à integração destes alunos no cotidiano da sala de aula.

A declaração de Salamanca reafirma o compromisso com a educação para todos e urgência da educação para crianças, jovens e adultos com necessidades especiais dentro do sistema regular de ensino.

Todas as crianças de ambos os sexos, têm direito fundamental à educação e que a elas deve ser dada a oportunidade de obter e manter um nível aceitável de conhecimentos;Cada criança tem características, interesses capacidades e necessidades de aprendizagem que lhes são próprias;Os sistemas educativos devem ser projetados e os programas aplicados de modo que tenham em vista toda a gama dessas diferentes características e necessidades;As pessoas com necessidades educativas especiais devem ter acesso às escolas comuns, que deverão integrá-las numa pedagogia centralizada na criança, capaz de atender a essas necessidades;As escolas comuns, com essa orientação, representam o meio mais eficaz de combater atitudes discriminatórias, de criar comunidades acolhedoras, construir uma sociedade integrada e dar educação para todos; além disso, proporcionam uma educação efetiva à maioria das crianças e, certamente, a relação custo-benefício 
de todo o sistema educativo. (DECLARAÇÃO DE SALAMANCA, 1994, p. 10)

De acordo com o Ministério da Educação, a inclusão não significa apenas matricular os educandos com necessidades especiais na classe comum, mas significa dar ao professor e à escola o suporte necessário à sua ação pedagógica, conforme o que prevê o artigo 59 da Lei de Diretrizes e Bases da Educação Nacional (BRASIL 1996).

Art. 59. Os sistemas de ensino assegurarão aos educandos com necessidades especiais: I - currículos, métodos, técnicas, recursos educativos e organização específicos, para atender às suas necessidades; II - terminalidade específica para aqueles que não puderem atingir o nível exigido para a conclusão do ensino fundamental, em virtude de suas deficiências, e aceleração para concluir em menor tempo o programa escolar para os superdotados; III - professores com especialização adequada em nível médio ou superior, para atendimento especializado, bem como professores do ensino regular capacitados para a integração desses educandos nas classes comuns; IV - educaçáo especial para o trabalho, visando a sua efetiva integração na vida em sociedade, inclusive condições adequadas para os que não revelarem capacidade de inserçáo no trabalho competitivo, mediante articulaçấo com os órgãos oficiais afins, bem como para aqueles que apresentam uma habilidade superior nas áreas artística, intelectual ou psicomotora; V - acesso igualitário aos benefícios dos programas sociais suplementares disponíveis para o respectivo nível do ensino regular.

Temos muitas leis e documentos onde os direitos destes alunos são assegurados. Embora o papel das leis seja importante no processo de transição para que ocorra a inclusão, elas, por si só, não garantem as mudanças necessárias. É importante construir critérios para a organização das salas de aula inclusivas, considerando o número de alunos, refletindo a realidade social, observando a qualidade desse atendimento. A escola deve ser um ambiente que reflete a sociedade como ela é, sendo que os alunos incluídos deverão ter seu espaço e oportunidades garantidas.

Todas as crianças são únicas, diferentes e especiais, e é na escola que elas terão as mesmas chances para desenvolver o seu potencial, em conjunto, umas aprendendo com as outras, todas percebendo semelhanças, diferenças, singularidades, mas crescendo e conquistando o direito de ser diferente.

De acordo com Souza e Santos (1995, MANTOAN, 2003 p. 34) é preciso que tenhamos o direito de sermos diferentes, quando a igualdade nos descaracteriza e o direito de sermos iguais quando a diferença nos inferioriza.

\section{Consideraçóes finais}

A proposta da inclusão não é apenas a de inserção social, mas da participação plena dos alunos com deficiência, da otimização do processo de aprendizagem segundo a possibilidade de cada um. Pretende oferecer apoio aos professores e aos alunos para que estes alcancem níveis superiores de aprendizagem.

Os pais também têm grande contribuição para dar à escola quando são parceiros no processo de avaliação das necessidades educacionais especiais e nas tomadas de decisóes sobre 
as questôes de seus filhos. Os professores necessitam de formação para trabalhar com alunos com diferenças significativas, sejam sociais, culturais ou com deficiências; no percurso formativo precisam adquirir habilidades para trabalhar com grupos heterogêneos, com os sistemas de monitoria e tutoria, os quais trazem benefícios e enriquecimento para os alunos e professores, todos podem aprender mais.

Enquanto professores, devemos sempre manter grandes expectativas, sonhar e lutar em relação a aprendizagem de todos os alunos dentro de suas diversidades, linguagens e manifestaçôes de crescimento e desenvolvimento pois, se conseguirmos pequenos avanços na aprendizagem explorando talentos, possibilidades ou melhorar alguma qualidade natural de cada aluno, já será um grande passo.

Exigem-se assim decisóes e açôes pedagógicas compartilhadas entre profissionais atuantes na escola, profissionais da saúde, pais e os próprios alunos. O currículo deve servir como roteiro ao professor e deve ser flexível e modificado de acordo com as aprendizagens individuais. Aos educandos cabe a parte de vivenciar, participar e colaborar com atividades, respeitando a si próprio e aos outros. $\mathrm{Na}$ perspectiva inclusiva a educação especial passa a ser um conjunto de técnicas e serviços organizados e colocados à disposição na escola comum. Enfim, todos os conhecimentos científicos já desenvolvidos devem estar à disposição de cada aluno na escola.

Portanto, pensar a inclusão como responsabilidade coletiva exige uma mudança de paradigma e um novo olhar sobre o ser humano. É fundamental uma prática pedagógica voltada para as diversidades onde os professores, juntamente com a comunidade escolar estejam abertos e flexíveis para acolher a todos.

\section{Referências}

LOCATELLI, Adriana Cristine Dias. Fundamentos da educaçáo especial: pedagogia / Adriana Cristine Dias Locatelli. Edilaine Vagula. São Paulo: Pearson Education do Brasil, 2009.

LÜDKE, Menga; ANDRÉ, Marli E. D. A. Pesquisa em educação: abordagens qualitativas. São Paulo: EPU, 1986.

MANTOAN, Maria Teresa Égler e colaboradores. A integraçáo de pessoas com deficiência: contribuiçóes para uma reflexáo sobre o tema. São Paulo: Memmon: Editora SENAC, 1997.

MANTOAN, Maria Teresa Égler. Inclusão Escolar: O que é? Por que? Como fazer? São Paulo: Moderna, 2003

SOUZA, Paulo Nathanael Pereira de; SILVA, Eunides Brito da. Como entender a nova LDB; Lei no 9.394/96. Sáo Paulo: Pioneiro, 1997.

SILVA, Samira Fayez Kfouri da. A açáo docente e a diversidade humana: pedagogia / Samira Fayez Kfouri da Silva, Sandra Regina dos Reis Rampazzo, Zuleika Aparecida Claro Picassa. São Paulo: Pearson Education do Brasil, 2009. 